\title{
QUADRUPOLE RELAXATION OF ${ }^{79} \mathrm{Br}$ NUCLEI IN FERROELECTRIC $\left(\mathrm{CH}_{3}\right)_{4} \mathrm{NCdBr}_{3}$ (TMCB)
}

\author{
D.F. Baisa, E.D. Chesnokov,
}

Institute of Pliysics, Ukrainian Acad. Sci., Prospckt Nauki 16, 252028 Kiev, Ukraine

AND Z. CZAPLA

Institute of Experimental Plysics, University of Wrockaw

M. Borna 9, 50-204 Wroclaw, Poland

(Received April 13, 1994)

\begin{abstract}
Investigations of temperature dependence of a nuclear quadrupole spinlattice relaxation lime of ${ }^{79} \mathrm{Br}$ nuclei in ferroclectric $\left(\mathrm{CH}_{3}\right)_{4} \mathrm{NCdBr}_{3}$ are presented. It is sliown that in paraelectric phase in the vicinity of phase transition temperature relaxation process is determined by critical fuctuations of electric field gradient. In ferroclectric phase relaxation is related to three different mechanisms, namely: lattice vibratious, $\mathrm{CHI}_{3}-$ group reorientations and TMA cation motions. According to the results of measurements it is concluded that the pliase transition is connected with ordering of TMA cations.

PACS numbers: 64.70.Kb
\end{abstract}

Tetramethylammonium tribromocadmate $\left(\mathrm{CII}_{3}\right)_{4} \mathrm{NCdBr}_{3}$ (TMCB) belongs to the family of crystals with a gencral chemical formula $\left(\mathrm{CII}_{3}\right)_{4} \mathrm{NMX}_{3}$, where $M=M n, \mathrm{Ni}, \mathrm{Cd} ; \mathrm{X}=\mathrm{Cl}, \mathrm{Br}, \mathrm{I}$. Among them $\left(\mathrm{CI}_{3}\right)_{4} \mathrm{NMnCl}_{3}$ (TMMC) crystal has been widely studied as quasi-one-dimensional magnetic system with infinite chains of $-\mathrm{Mn}-\mathrm{Cl}_{3}-\mathrm{Mn}_{\mathrm{n}}-\mathrm{Cl}_{3}-$ separated by tetramethylammonium cations (TNA) $[1,2]$. Similarly as in the case of TMMC isomorphous crystals of $\left(\mathrm{CII}_{3}\right)_{4} \mathrm{NCdCl}_{3}$ (TMCC) and $\left(\mathrm{CH}_{3}\right)_{4} \mathrm{NNiCl}_{3}$ (TMNC) exhibit structural phase transitions from hexagonal high-temperature phase to monoclinic low-temperature phase $[3,4]$. It was shown that in high-temperature phase of these crystals TMA cations are disordered $[2,5]$ and order-disorder phase transitions are related to the ordering of TMA cations and small shifts of the metal-halogen chains [4]. TMCB crystal is another member of this family and undergoes a structural phase transition of the first order from hexagonal room temperature phase (space group $P 6_{3} / \mathrm{m}$ ) to another hexagonal phase (space group $P 6_{1}$ ) and disordered states of TM $\Lambda$ cations in paraelectric and ordered in ferroclectric phase are found in it [6-8]. The low-temperature phase exhibits ferroclectric properties along the $c$-axis. Spontancous polarization is equal to $1.2 \times 10^{-3} \mathrm{C} / \mathrm{m}^{2}$ at $125 \mathrm{~K}$ [9]. NMR investigations of molecular dynamics in 
TMCB [10] showed that predominant mechanisms of proton relaxation are reorientations of $\mathrm{CII}_{3}-$ groups and TMA cations. NMR measurements did not show any peculiarities related to the phase transition at $163 \mathrm{~K}$. Most probably very fast reorientations of $\mathrm{CH}_{3}-$ groups mask slow motions of TMA cations and their changes connected with the phase transition. Temperature dependencies of NQR frequencies of ${ }^{79} \mathrm{Br}$ observed previously $[11,12]$ confirmed the first-order phase transition. Nakamura [11] proposed that the transition to the ferroelectric pliase is related to the displacement of the bromine atoms. On the contrary, our analysis [12] showed that bromine atoms did not take a direct part in the phase transition and critical behaviour of resonance frequencics is caused by the interaction with spontaneous polarization of the crystal. To obtain further information related to the role of bromine atoms in the mechanism of the phase transition and study molecular and lattice dynamics the temperature dependence of spin-lattice relaxation time $T_{1}$ of ${ }^{79} \mathrm{Br}$ nuclei was measured. Measurements were performed by means of pulse spectrometer of ISS-2-13 type using two-pulse and four-pulse (for small values of $T_{1}$ ) methods in the temperature range 77-310 K. Results of relaxation time measurements are shown in Fig. 1. As it can be secn in Fig. 1

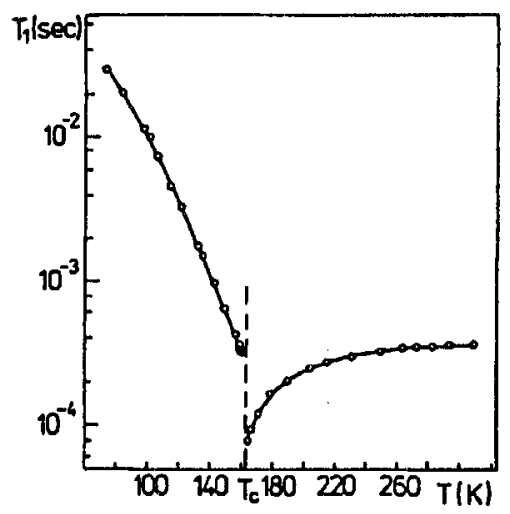

Fig. 1. Temperature dependence of quadrupolar spin-lattice relaxation time $\left(T_{1}\right)$ of bromine nuclei in $\left(\mathrm{CH}_{3}\right)_{4} \mathrm{NCdBr}_{3}$.

spin-lattice relaxation time exhibits strong temperature dependence and changes in the range of three orders of magnitude in the temperature range under investigation. As the quadrupolar relaxation is defined by fluctuations of electric field gradient (EFG) tensor in a site of resonant nucleus: $T_{1}^{-1} \sim J(\omega)$, where $J(\omega)-$ spectral density of fluctuations, critical behaviour of some vibrational modes of crystal lattice results in anomalous temperature dependence of relaxation time on approaching the phase transition temperature. Such an anomalous behaviour of $T_{1}$ essentially depends on interaction character of critical branch vibration with electric field gradient on a nucleus. According to theoretical considerations for various types of interactions [13] temperature dependence of $T_{1}^{-1}$ is given with a power formula

$$
T_{1}^{-1} \sim\left(T-T_{\mathrm{c}}\right)^{-n},
$$


where $n=2,3 / 2,0,1 / 2$ in dependence on kind of action or logarithmic formula

$$
T_{1}^{-1} \sim \ln \left(T-T_{\mathrm{c}}\right) \text {. }
$$

In our case in high-temperature (paraclectric) phase on approaching the temperature of phase transition the relaxation time $T_{1}$ strongly decreases to the value of $70 \times 10^{-6} \mathrm{~s}$ according to the formula

$$
T_{1} \sim\left(T-T_{\mathrm{c}}\right)^{1 / 2} .
$$

It gives evidences for contribution of critical modes to the electric field gradient fluctuations. On approaching $T_{\mathrm{c}}$ in ferroclectric phase decrease in $T_{i}$ to the value of $3 \times 10^{-4} \mathrm{~s}$ is observed and this dependence resembles the critical behaviour, too. Ilowever, detailed analysis of experimental data did not show any critical behaviour of relaxation time below $T_{\mathrm{c}}$ (in ferroelectric phase). In this phase the spin-lattice relaxation velocity $\left(T_{1}^{-1}\right)$ is well described as a sum of three contributions with a formula

$$
T_{1}^{-1}=a T^{2}+b \exp \left(-E_{1} / k T\right)+c \exp \left(-E_{2} / k T\right),
$$

where

$$
a=5.82 \times 10^{-3} \mathrm{~s}^{-1} \mathrm{~K}^{-1}, \quad b=5.57 \times 10^{5} \mathrm{~s}^{-1}, \quad c=6.25 \times 10^{9} \mathrm{~s}^{-1}
$$

and

$$
E_{1}=1.95 \mathrm{kcal} / \mathrm{mol}, \quad E_{2}=4.86 \mathrm{kcal} / \mathrm{mol} \text {. }
$$

In Fig. $2 T_{1}^{-1}$ dependence obtained from experimental data (points) and the best fitting of Eq. (4) (curve 4) and dependencies of particular contributions

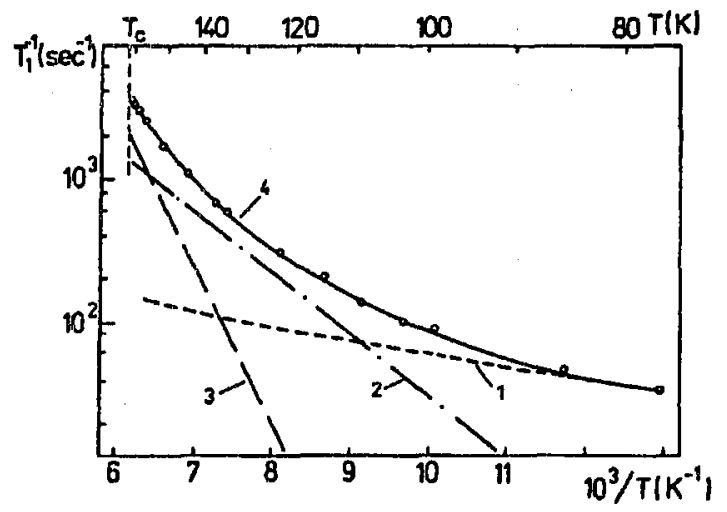

Fig. 2. Dependence of relaxation velocity $\left(T_{1}^{-1}\right)$ in ferroelectric phase of $\left(\mathrm{CH}_{3}\right)_{4} \mathrm{NCdBr}_{3}$ (points and curve 4) and particular contributions to relaxation: 1 $T_{1}^{-1}(1)=a T^{2}, 2-T_{1}^{-1}(2)=b \exp \left(-E_{1} / k T\right), 3-T_{1}^{-1}(3)=c \exp \left(-E_{2} / k T\right)$ on inverse temperature. 
(curves 1-3) to total relaxation as functions of $1 / T$ are presented. The first term in Eq. (4) (curve 1) in Fig. 2 describes usual Raman two-phonon process (energy exchange between the nuclear spin system) which is predominant at low temperatures. In this process the difference of incident and scattered phonon frequencies is the same order of magnitude as the NQR frequency. Such processes are more effective than direct interaction of clectric field gradient and lattice vibrations. According to qualitative theory of quadrupolar relaxation based on Debye's model for lattice vibrations and model of point charges for electric field gradient [14] temperature dependence of $T_{1}{ }^{-1}$ is given as

$$
\begin{aligned}
& T_{1}^{-1}=a+b T^{2} \quad \text { for } \quad T>0.5 T_{\mathrm{D}}, \\
& T_{1}^{-1}=c T^{7} \quad \text { for } \quad T<0.02 T_{\mathrm{D}},
\end{aligned}
$$

where $T_{\mathrm{D}}-$ Debye's temperature. IIcre one can notice that for TMCB $T_{\mathrm{D}}<150 \mathrm{~K}$. Second and third terms describe thermally activated rcorientational motions with energies $E_{1}$ and $E_{2}$. It is difficult to explain relativcly low values of two activation encrgies with any rcorientational motion of such heavy particles as bromine atoms. These valucs are comparable in magnitude to the activation energies of $\mathrm{CII}_{3}$ - group rotation $(1.6 \mathrm{kcal} / \mathrm{mol})$ and 'TMA cation tumbling $(4.6 \mathrm{kcal} / \mathrm{mol})$ obtained from proton ( $\left.{ }^{1} \mathrm{II}\right)$ magnetic spin-latticc relaxation measurements (NMR). Such a good agrement between activation energics obtained from proton magnetic resonance and bromine quadrupolar relaxation leads us to conclusion that the same thermally activated motions, namely: $\mathrm{CII}_{3}-$ group reorientations and TMA cation tumbling are responsible for relaxation obscrved both in NMR and NQR measurements. In this way, spin-lattice relaxation of bromine nuclei results from electric field gradient fluctuations (despite of lattice vibrations) caused by reorientational motions of $\mathrm{CII}_{3}-$ groups (straight line 2 in Fig. 2) and tumbling of TMA cations (straight line 3 in Fig. 2). Near the phase transition temperature the privileged mechanism is related to TMA cation tumbling. The obtained results confirm our previous assumption [12] that bromine nuclei do not take the direct part in the transition and that in TCMB we deal with the order-disorder type phase transition accompanied by ordering of TMA cations.

This work was supported by the research project No. 201289101.

\section{References}

[1] B. Morosin, E.J. Graeber, Acla Crystallogr. 23, 766 (1967).

[2] M.T. IIutchings, G. Chirane, R.J. Brigeneau, S.R. Ilolt, Phys. Rev. B 5, 1999 (1972).

[3] B. Morosin, Acla Cryslallogr. B 28, 2303 (1972).

[4] P.S. Peercy, B. Morosin, G.A. Samara, Phys. Rcv. B 8, 3378 (1973).

[5] P.S. Peercy, B. Morosin, Phys. Lelt. A 36, 409 (1971).

[6] P. Vanck, M. Havrankova, F. Smutny, B. Brezina, Ferroelectrics 109, 51 (1990).

[7] T. Asali, K. Ilasebe, K. Gesi, Acla Crystallogr. C 46, 2252 (1990).

[8] T. Asahi, K. IIascbe, K. Gesi, Acla Crystallogr. C 47, 1208 (1991).

[9] K. Gesi, J. Phys. Soc. Jpn. 50, 432 (1990). 
[10] K. Venu, V.S.S. Sastry, J. Ramakrishna, J. Phys. C 20, 1519 (1987).

[11] S. Islimaru, N. Nakamura, J. Phys. Soc. Jpn. 61, 1787 (1992).

[12] D.F. Baisa, E.D. Chesnokov, Z. Czapla, S.V. Pogrebnyak, I.G. Vertegiel, Acla Phys. Pol. A 84, 271 (1993).

[13] J.G. Kubarev, M.A. Popov, Yadernaya magnilnaya relaksaciya $i$ dinamika spinovykh syslem, Krasnojarsk 1982, p. 52.

[14] J. Vau Kranendonk, Plyysica 20, 781 (1951). 